\title{
9 Professional Learning as Attuning, Connecting and Sensitising
}

\begin{abstract}
This chapter takes up the ideas presented in Part II - times, spaces, bodies, and things as essential dimensions of professional practice and learning. The focus here is specifically on how professionals learning about, from and with the people they are there to help (in this case, families with young children), and each other. The chapter begins by laying out a distinctive conceptualisation of professional learning in practice. This sees learning and practice as entangled, but asymmetrically related. The idea of learning as involving the production, maintenance, restoration, repair and modification of textures is presented. These concepts are then entangled with empirical data, furthering the conceptualisation of attuning (introduced in Part II), and showing how learning performs crucial connecting and sensitising functions, through textural and epistemic work. A focus on handover practices reveals details of these ideas, and also provides a platform to explore professional learning in practice as choreographed to varying degrees. The whole chapter is framed in terms of the intensification of learning imperatives associated with partnership-based approaches to professional practice. The need to learn as a part of practice, and the need to act amid conditions of uncertain, incomplete and ambiguous knowledge is also highlighted. The chapter shows how a sociomaterial approach, combined with the novel framework presented here, offers valuable insights into challenges associated with contemporary professional practice.
\end{abstract}

\section{Introduction}

This is the first chapter in Part III. It takes the ideas developed through Part II as a basis for exploring questions more directly focused on learning. Here in Chapter 9 the focus is on professional learning in practice, while in Chapter 10, the focus is on professional expertise within partnership understood as pedagogic work. The practices discussed here and in Chapter 10 are tightly interwoven, and cannot be cleanly separated. As with the dimensions of Part II, the two chapters here reflect a nuanced yet imperfect analytical distillation, highlighting different features of a complex, multifaceted set of linked practices. The framework from Part II is carried forward here into the analysis of professional learning in practice. Chapters 5 8 focused respectively on times, spaces, bodies, and things. These were presented as four essential dimensions of practices and their changing connectedness in action. I signaled that these dimensions are not separate from questions of learning, but held off from developing this point. 
The conception of professional learning in practice builds on the framework presented in Chapter 3. I treat learning as something entangled with but analytically separable from practices. This relationship is asymmetrical or non-reversible in that professional learning arises through practices, but I do not assume all practices bring about learning. One (learning) can be diffracted out from the other (practice). I conceptualise learning as changes in knowing (interpreting and acting) that occur in and further the ends of a particular professional practice. Such learning involves repositioning oneself in relation to aspects of knowledge, and others' actions, through changing interpretations and possibilities for action (Edwards 2000). This difference refers to producing new textures, modifying, restoring or repairing them, or maintaining them in the face of other change. This is based on a notion of stability and change as co-present features of practices (Schatzki 2013; Price et al 2012). Specifically in this chapter, I take up these ideas and those of attuning (see Chapter 7) in order to argue that professional learning in practice has crucial connecting (textural) and sensitising (epistemic) functions. This has implications for the nature of professional learning: it creates particular imperatives to learn and foci for the use and emergence of professional expertise.

Linking these premises to the arguments developed in Part II surfaces a range of crucial questions about learning in professional practice. How are temporal, spatial, embodied and material textures produced, repaired, restored, modified, and maintained? What does this tell us about the needs for and functions of learning in professional practices? If all the learning required to perform a practice cannot be specified in advance, how do practices go on? Why must professionals learn as they perform their work, what do they learn, and what difference does this make to what happens? How can we preserve something distinctive about the idea of learning while remaining faithful to the ontological and epistemological commitments of sociomaterial and practice-based approaches?

These questions frame my analysis of particular practices of the Residential Unit and the wider conceptual arguments that I develop through it. The latter contribute to how we understand relationships between learning and practice more generally. In summary, these broader arguments are as follows. Practices based upon partnerships between professionals and service users produce imperatives for professionals to learn as an ongoing part of performing their work. In the context of the Residential Unit, learning enables staff to become intimate outsiders in family life. The four dimensions of times, spaces, bodies and things provide a foundation for describing learning, making visible features of what is learned and how that might otherwise be overlooked. I describe these in terms of attuning. This is both (i) performed personally as each member of staff but draws on a repertoire of shared practical understandings and aesthetic sensibilities; and (ii) a collective accomplishment, in which emerging knowledge is shared, questioned, and discussed, ensuring continuity and coordination across shifts and professions, and working with knowledge that is provisional, contingent, and unstable. 
Learning fulfills two crucial and related functions in ensuring practices can go on in the constant co-presence of stability and change. With regards to its connecting function, connectedness in action is not a given, but must be accomplished. Once established, connections are not independently secure - work is required to maintain them. Learning produces textures that hold practices together; it helps to modify, repair or restore textures when connections are strained, broken or lost; and it helps to maintain textures in light of other changes. With regards to its sensitising function, learning enables practices to respond with agility to changes, making them sensitive to subtle variations, preventing rigidity or stasis.

Many professional learning practices, such as handover, perform both textural work and epistemic work. Textural work produces, modifies, maintains, repairs and restores connectedness in action. Epistemic work responds to the partial, contingent and unstable nature of knowing in work. Practices of professional learning display varied degrees of choreography, involving patterns of rhythms, bodily arrangements and movements, talk, and interaction with objects. The concept of prefiguration is helpful in understanding how this choreography is accomplished and why it varies.

This chapter is structured as follows. First I will focus on the idea of partnership between professionals and service users (in this case, families), showing how the attempt to work in partnership intensifies the need for professionals to learn as an ongoing and always unresolved feature of their work. Then I will link the present chapter back to Part II by exploring professional learning as attuning, first in more personal, and then in more collective forms. This provides a foundation for the following section which explores learning as connecting and sensitising. These arguments are developed in more conceptual form first, and then illustrated and further explored through detailed analysis of handover practices.

\section{Partnership and professional learning}

Karitane seeks to work in partnership with parents (see Chapter 2). This approach moves away from expert-led models of care in which professionals diagnose deficiencies, set priorities, determine solutions, and solve problems for families. Instead the emphasis is on listening, mutual recognition of different but equally valued forms of knowledge (both professional expertise and ways of knowing within families), negotiation of goals, joint exploration and evaluation of strategies to move forward, and support in implementing them.

Partnership is one manifestation of a much wider trend emerging across a range of professions. This trend involves significant changes in relationships between professionals and service users (Fenwick 2012; Fowler et al 2012a, b; Hopwood 
2013, 2014, forthcoming; Hopwood \& Clerke 2012; Hopwood et al 2013; Rossiter et al 2011), and includes ideas of coproduction (Dunston et al 2009). Referring specifically to partnership, Hook's (2006) conceptual review identified the following central and distinctive features: relationship focus, shared power, shared decision-making and patient autonomy. At Karitane the FPM (Davis \& Day 2010; Day et al 2015) has been adopted as the framework through which to embed a partnership-based approach. As described in Chapter 2, it reflects the broader trends, while having particular features of its own. Uptake of the FPM at Karitane reflects decisions at the New South Wales State level to encourage partnership-based work with families, and the specific choice of FPM as a primary means to deliver this. FPM combines an explicit (and evolving) conception of the helping process with in-service training and supporting guides to facilitate reflection (Day et al 2015).

Working in partnership means that learning in professional practice takes on new forms and functions. Part III of this book is structured around the idea that reciprocal learning is required if partnership is to be accomplished. It does not guarantee effective partnerships that live up to policy ideals or qualities outlined in conceptual models. However, I argue that without learning in both directions between professionals and families, partnership cannot be achieved. Chapter 10 takes up the idea that partnership involves reframing the helping process as one in which professionals facilitate parents' learning, and explores what they learn, and the (professional) practices that bring this learning about. For now, the focus is on the fact that work at the Residential Unit requires professionals to learn from, about and with the families they are working with, and from each other.

Chapter 2 showed how diverse the families attending the Residential Unit are. They come from across New South Wales, living in major urban centres, regional towns, and rural and remote locations. Variation is evident across a range of social and demographic indicators, including employment status, class, race, ethnicity, age, migration history, and family structure (single/dual parent etc). Some parents are experiencing challenges with their first child, others with their third; some struggling to cope with twins or triplets. How parents feel about themselves as parents is assessed through the Karitane Parenting Confidence Scale (KPCS; see Črnčec et al 2008). Admission scores on the KPCS vary widely from family to family, often producing a wide range within the 10 or so families present each week. Other factors produce yet further complexity and difference among the families whom the Unit supports, such as the incidence of perinatal mood disorders, intra-family conflict and domestic violence, histories of drug and alcohol abuse, and parents' own experiences as children.

This diversity creates an ongoing demand for learning in professional practice. Even without the idea of partnership, it becomes immediately obvious that any services aiming to offer support to this client base must incorporate practices through which professionals learn about their clients. Middleton and Brown 
(2005) make a similar point in their description of neonatal intensive care. They show how the regular appearance of new staff, patients and technologies means that effort must be expended to hold the unit together as a functional entity. In Schatzki's terms, hanging together is not established and then self-perpetuating.

Professionals on the Unit can assume little about who will arrive each Monday, beyond what is known from referrals and intake interviews (but even this knowledge is treated as incomplete, uncertain, and contingent; see below). What cannot be assumed must be learned. This learning cannot happen before the process of working with families begins. The temporality of learning completed prior to practices is disrupted: the need to learn arises as practices unfold.

Partnership intensifies this learning imperative. It also makes what is learned more significant, because the practices of support that emerge over the course of each week are highly shaped by what staff come to know about each family. Partnership places explicit emphasis on professional learning at all stages of the helping process. Right from the start, it promotes extended and open listening to parents, rather than a form of history taking that fills out information that professionals deemed relevant before the event ${ }^{1}$. Learning then continues in the ways professionals are expected to explore how parents construe their situation and the difficulties they face, what their priorities and values as parents are, what strengths and protective factors may be available to draw on, how they respond to challenges presented to them (often in the form of trying out new techniques for settling or managing tantrums, for example), and how what they are doing on the Unit affects their esteem, capacity and confidence as parents, and its prospects for family well being in the long term.

Partnership also determines the 'what' of learning between professionals and families. In order to work in partnership, professionals must not only learn about families. The idea of partnership implies a particular kind of relationship, which in turn influences how professionals learn with families. Moreover, partnership deflects learning content about families from the centre. Instead, there is a much more relational emphasis, meaning that much of this learning is focused on what it means to work with a particular family. In other words, it is not just the family that is being learned about. It is also (perhaps more, or more significantly) the relationship between the family and the professionals working with them (see Hopwood forthcoming).

In other words, partnership requires professionals to learn quickly and widely about families from the moment of first interaction. It then frames the helping pro-

\footnotetext{
${ }^{1}$ See Edwards \& Apostolov (2007) for a discussion of co-configuration and how professionals learn through listening to service users - ideas that are developed in relation to the present study concept in Hopwood (forthcoming).
} 
cess as one in which professionals continue to learn about, from and with the people they are helping, including learning what kind of relationship needs to be established in order to secure the positive change and outcomes that partnership is supposed to deliver. In partnership this learning is not knowledge that sits passively in practitioners' heads. It is learning that takes the form of action and changes action, and emerges through and with action. Partnership involves working in a responsive, unpredictable way - as the week unfolds, professionals continue to learn about families, and their actions change as a result. No learning sews up practices for the rest of the week. In fact, what is learned can be quite unstable. This has implications for the kinds of knowledge or knowing that underpin learning and practices, as discussed below with regard to contingent epistemology.

Thus partnership creates an imperative for learning that has a sensitising function. This links to the fifth key argument listed above, Here, this means practices that adjust to the particularities of each family, and the changes in those families. Partnership requires agility not only to a diverse client base, but temporal agility, too. I argue that this is accomplished through particular kinds of learning, without which it would not be possible.

This learning is never complete. I mean this in both the sense that it is never finished, but also that it is never exhaustive in its coverage of the matter at hand. Professionals working in partnership with clients are perpetually acting in a situation in which their learning (whether as individuals or a collective body of staff) is unresolved. No duration or quality of pre-service training could mitigate this. The demand for ongoing learning comes not from a deficiency in professional knowledge or skills, but emerges in the course of practices themselves. Even the learning on-the-job is always incomplete. This is not a failure but rather a necessary condition of the kind of work being performed.

Partnership practices thus present an inherent and perpetual knowledge challenge for professionals. They must continually act in conditions in which there can never be complete knowledge of whom they are working with or what to do next. Far from the notion of evidence-based practice, in which robust empirical results provide clear directions on how to act, the view I present below is one characterized by partiality, uncertainty and fragility of knowledge, where knowledge is constantly changing through practices of learning which inform but do not direct what to do next, and where decisions and actions in this regard have a significant aesthetic basis. To understand this, we must first explore how professionals attune to the families they are working with. Having done this, we can investigate the connecting and sensitising functions of professional learning. The former focusing on the maintenance of textures, the latter on the epistemic work that accompanies the unresolved knowledge challenges outlined above. 


\section{Professional learning as attuning}

Attuning provides a foundation for much professional learning on the Unit. It is through attuning to families that staff develop forms of knowing in practice that produce, modify, repair, restore and maintain textures, and that ensure support remains sensitive to the strengths, priorities and vulnerabilities of each family. In this section I build on Part II, highlighting the role of attuning both as a personal and collective accomplishment. The later sections on learning as connecting and sensitising, and the detailed exploration of handover practices, refer (sometimes implicitly) to the forms of knowing developed through practices of attuning described here.

Professionals on the Unit are constantly attuning to the families they are working to support. I refer to attuning to emphasise it as a set of practices that are enacted, performed. Attunement can be understood as an effect of this attuning, what is accomplished. This was discussed in Chapter 7 with specific reference to the embodied performances of noticing, attending, and sense-making enacted as professionals go about their work, and in Chapter 8 with reference to the changing materialities of the playroom. As a consequence of the uncertainties and contingencies described above, this attunement is never assumed to be complete or stable, hence work of attuning is never finished, but rather is provisional and continues to be done throughout each week. As a form of connection between professionals and families that is constituted in action, attunement can be understood as a texture (Gherardi 2006), comprising four essential dimensions of times, spaces, bodies and things (see Chapter 3, and Part II). The process of learning about families depends on nuanced, emergent attuning to those families. The knowledge arising from this reflects the degree and nature of attunement, which in turn is part of the balancing act required in achieving and maintaining appropriate intimate outsidership.

It is important to recall the relational nature of attuning, as discussed in Chapter 7. This refers to attuning as involving practical intelligibility, active processes of sense-making and aesthetic judgement, such that, for example, sounds become meaningful soundscapes, and co-presence turns postures and gestures into bodyscapes bursting with new knowledge. Attuning is also relational in the sense being shaping what is attuned to through responses to it (ie subsequent actions).

Some practices of attuning can be understood as accomplished through personal performances, while others are better understood as more collective achievements, producing a collective sensibility. I use the word personal rather than individual, stressing that all practices are relational, never performed in a social or material vacuum. Personal attuning is always done through actions, interactions with and reactions to others. Collective attuning is done through connected actions per- 
formed by bodies who act and feel as selves with individual integrity. However just as the four dimensions of Part II proved useful points of analytical departure, so here I take personal and collective qualities as an analytical device, a means to diffract out different aspects of attuning. Attuning requires and produces connections in action constituted in the four essential dimensions of times, spaces, bodies and things. The collective sensibility that partnership work with families demands rests on practices that attend to nuances of rhythm, produce and inhabit multiple, fluid spaces, including body geometries, enact aural, visual, tactile, olfactory and other body work, and which draw from, respond to, and modify material arrangements.

\section{Attuning as a personal performance}

I will now provide empirical illustrations of attuning and relate these to professional learning in practice. In doing so I refer back to much of what was discussed in Part II (especially Chapter 7, and also Chapter 8). Here, I bring the analysis into more explicit connection with ideas of learning in terms of the framework set out earlier in this chapter, by highlighting the creation, restoration, modification and repair of textures, or connections in action. These map back across all four dimensions discussed in Part II. The non-individual yet still personal nature of attuning is emphasized more clearly here, mapping practices of attuning across multiple bodies and artefacts. While attuning relies on skilled performances of noticing and sense making, a site ontology (Schatzki 2002, 2003) refers us to (social) practices, bundled with material arrangements as the 'place' where attuning happens, as the constituents of attunement.

Attuning relies on a particular professional body or bodies being present with families in order to notice, attend, and make sense. Individual actions lie at the core of what staff on the Unit learn about families and how they do so. These are also social in the sense that they instantiate, uphold and are governed by practices that are performed, in more or less similar ways by others, and recognized as such. Each performance of attuning draws on and upholds a repertoire of practices of attuning that share common practical understandings, general understandings, rules, and teleoaffective structures (see Chapter 3 ). Through these shared social features, individual performances feed collective sensibility. These performances and the presence associated with them can be understood in terms of the textures described in Part II.

Being there with families is to a large degree afforded by the spatial and temporal constitution of the Unit. It functions for 24 hours a day from Monday to Friday, within a relatively small part of a single building, although its boundaries are porous as both staff and families come and go during this period. While profession- 
als are not 'there' in family homes, they are 'there' at breastfeeding and meal times, during settling (whatever time of day or night), play, bathtime, toddler tantrums, and so on. When a member of staff is with parents and children, a coming together of trajectories (Massey 2005) has brought them to the Unit, this week, to this room, at this particular moment.

Being there is a coming together of bodies and things. It is not just a connecting of spatial and temporal trajectories that underpins attuning, but embodied and material presences and trajectories too. The embodied performances of noticing and sensemaking attune professional bodies to the bodies of parents and children (see Chapter 7). Body geometries (see Chapters 6 and 7) and material arrangements are always constituent dimensions of attuning: not only the bodies of people, but pens, behavior charts (see below; Figure 5.1), toys, food, breastmilk, bed sheets, cot wheels, music systems and so on (see Chapter 8). In other words, the temporal, spatial, embodied and material textures discussed in Part II produce the conditions in which performances of attunement can unfold.

In turn those performances produce new connections, modify existing ones (enriching them with new meaning), and may repair or restore those that had been broken or lost. For example, nurse Gillian ${ }^{2}$ had been there during a settling episode with a mother and child. She had been attuning to their bodies, attending to cries and signs of rest or distress in the child, observing and listening to the mother closely in order to gauge the degree of challenge the particular approach to settling was presenting, and how comfortable the parent was in her response to this challenge. The outcome was a decision to move the cot into the main (parents') bedroom, producing new material assemblages that in turn affect the body geometries between parents and child.

Many performances of attuning arise through informal and spontaneous interactions. These are not accidental though. On the contrary, the frequency of opportunities to attune reflects the textures that are constantly produced through practices described in Part II. 'Cruising' the corridors - walking slowly up and down with an air of availability (see Chapter 7) - is punctuated by peering through nursery windows, glancing or popping into the playroom, dining room, and guest lounges. While each member of staff is always assigned to work with more than one family, the increased staffing levels earlier in the week make them available to be present more of the time when learning about families is particularly intense.

Asking questions is crucial to attuning and the professional learning associated with it. While much is made of observing, listening, touching (infants), and smelling (nappies), knowing in practice that connects professionals and families also depends heavily on verbal exchanges. My point is not so much that learning hap-

\footnotetext{
${ }^{2}$ As always in this book, aliases are used when referring to staff and clients.
} 
pens through asking questions (this is obvious and well documented in literature). However knowing what questions to ask, and being present in circumstances when doing so is possible are both accomplishments in their own right. When Nurse Rachel accompanied Kirsty and her son Harry to their rooms, ready to conduct an admission interview, she asked: "Where's he up to?", referring to his feeding and sleep - prompting a verbal account from Kirsty here that Rachel translates and documents in the behavior chart (see Figure 5.1 for an illustration). "How do you think he'll be, this might take some time?", she asks, linking the rhythms of Harry's up and down times to the present clock time and the temporalities of admission; they decide to keep Harry there on the bed with them. Later, as Kirsty fills out one of the forms in admission, Rachel engages with Henry, stroking him and laughing: "His chin is a bit dry, has he started dribbling?". Kirsty replies yes, and directs Rachel to look at his right cheek that appears red compared to the left one. We can see here how Rachel used specific questioning, as well as visual and tactile attention, to attune to Kirsty and Harry. All the questions prompt responses that are attended to and which inform actions: adjustments to temperature, decisions about the presence and arrangement of bodies, markings on the behavior chart, discussions about dribbling, and so on.

Opportunities to attune through questioning are created through the spatial practices of the Unit. In particular, the heavy foot traffic around the nurses' station (see Chapter 6) means that when nurses are not with particular families, they are still very likely to encounter parents and children. I struggled to find in my notes an instance when a parent passed by the nurses' station without some interaction with a member of staff. Of course not all questions were posed by nurses - parents often ask things of staff - but the textures produced around the nurses' station were replete with questioning: How are things going? What are your plans? Did he manage a wee? Do you need anything from us? Would you like to join the toddler group?

Questioning is also systematically folded into more structured and planned encounters between staff and families. In these, as with the example of Rachel in admission with Kirsty and Harry above, other practices of attuning are also performed, but the questioning is shaped by a particularly strong patterning and tied closely to forms of materialization. Admission, the daily review of progress and goals, and discharge summaries are all prefigured by paper forms. These forms shape a line of questioning and provide a focus for attuning - a kind of skeleton curriculum for intended professional learning. Other textures and changes in knowing arise through these, such that the paperwork prefigures but does not confine the work of these interactions. Having considered the more personal aspects of attuning, I move on in the next section to consider its more social and collective features. 


\section{Attuning with and for others}

As mentioned above, other practices of attuning have a stronger collective quality. By this I refer to coordinated work between two or more professionals. This does not necessarily mean attuning done in a group by people working together at the same time. Indeed, I begin by exploring attuning that is spread out over space and time. This echoes Nicolini's (2011) description of how 'competence' in work results from different people's mutual alignment and co-orientation.

Attuning as collective sensibility produces and requires particular connections in action. Learning about families that results from actions of a particular individual is nearly always quickly connected into webs of knowing and acting across multiple bodies and artefacts. Various kinds of handover, weekly staff briefings, and case conferences are key formalized practices that translate personal attuning into shared ways of knowing the families in residence each week. Handover will be explored in detail later in this chapter.

For now, I will explore how what any one member of staff notices and makes sense is often done on behalf of and made available to others. Each professional acts as 'eyes and ears' (and nose and hands) for others. This may be simply as they take over during a break, or in the way that handovers, behavior charts (see Figure 5.1) and progress notes provide a continuous record of what has been noticed from shift to shift. Many performances are tantamount to multiple bodies attuning for and with each other. Below I present an excerpt from my fieldnotes that illustrates why noticing on behalf of others may be so important:

\footnotetext{
Thi, a playroom coordinator, has just been at the nurses' station talking to the in-charge nurse, Sarah, about an administrative issue. Having taken a couple of steps back towards the playroom, she turns, takes a step back towards me and Sarah, and says "um..?". Sarah responds, "Do you want to tell me in here?", indicating the handover room across from the nurses' station. All three of us enter the room and Sarah closes the door.
}

Thi: Taylor's mum. The way she talks... is she okay? Is she worried?

Sarah: She's under a lot of stress. She's pregnant with her fourth child, which wasn't expected. She sent her toddler home because she's quite overwhelmed. She's coping better today though.

Thi: Okay. Maybe I'll try to avoid any conversation that I think might overwhelm or upset her then. Oh! I can smell a baby. [She looks down and points to her trousers], I got spilled on!

Sarah: Or it could be me! [pointing to her fleece jacket] A baby shared himself with me.

Thi leaves, and Sarah writes "7 sad" on her left palm (Taylor and his mother being in room 7 that week). Later on, Sarah is giving handover to Ruth, who will be in-charge nurse for the next shift. She reports what Thi told her, and said "sometimes they see things 
in the playroom that we [the nurses] don't"; Ruth concurs and makes notes on her personal Clients in Residence sheet.

Here we see three bodies - Thi, Sarah, and Ruth - noticing for each other. Thi, for whom this was the first shift this week, relied on what Sarah knew and noticed about this mother earlier, in order to understand relevant aspects of this family case, and to inform her subsequent interactions with the mother. Sarah relies on Thi to be her 'eyes and ears' in the playroom where, as in-charge nurse, she can spend little time herself (Thursday shifts are busy coordinating discharge summaries, handovers and so on). Sarah's jotting on her hand (which as in-charge would not be seen by clients) enables Thi's noticing to be passed on to Ruth.

Similar chains of noticing between the playroom and nursing staff were evidence in another, sad, case of a mother who had lost her third child at a very young age. Throughout the week, staff were working to support her with her surviving children, but of course her response to the death was a key focus of their attention. One of playroom coordinators, Anh, commented in the Tuesday briefing that this mother told her and other parents (and me) that she has three children. Anh had noticed only two children named on the Clients in Residence form and was curious. The in-charge nurse leading the briefing noticed this as significant, as it was not consistent with the way this mother had talked with some nursing staff as a 'mother of two'. The point was not to question the mother's truthfulness or to suggest her actions were wrong, but to build a more complete picture of how this mother was managing her situation. Anh's attuning connected a minor spoken cue with a material record, and though this she became the 'listening ears' for the nursing staff - not only those present at the briefing, but those whom subsequently participated in co-producing textures and sensitivity in handover. Just as any account of noticing resists description on terms upon which it is performed by isolated individual bodies, so these examples (and all others) show how bodily performances of noticing are intertwined with the material environment.

Having discussed the knowledge work associated with attuning, I can now use this as a platform for exploring what learning in the course of professional practice accomplishes.

\section{Two functions of professional learning in practice}

The previous section described professional learning as a process of attuning to relevant features of work - in this case the families towards whom the overarching ends or purposes of professional practices on the Unit are oriented. This section takes the analysis in a related but distinct direction, focusing on the functions learning plays in the broader set of practices that unfold each week. I discuss these 
in terms of (i) textural work and connecting, and (ii) epistemic work and sensitising. These are discussed in more conceptual terms below, before taking handover practices as a concrete reference point through which these and many related ideas will be illustrated and expanded.

It is important, briefly, to revisit the theoretical assumptions that accompany this idea (see Chapter 3). The learning I refer to here is not understood in terms of parcels of knowledge that arise in individual's heads or get passed (transferred) from one to another. I conceive it in sociomaterial, specifically practice theoretical terms. Learning is an effect of doings and sayings enacted amid, with, and attuned to material arrangements. Does this means individuals are not learning, and their knowledge is not changing? No. But it does take individuals and cognition away from the centre of the picture. Yes, particular professionals learn new things. But what is learned, how it is learned, and the important effects of this learning, are not well understood in terms of a person-centred analysis. Instead, I argue learning in professional practice is accomplished through the actions and interactions of multiple actors - human bodies and other objects. As outlined before, I treat learning and practice asymmetrically: learning is always performed, always accomplished through practices, but not universally arising in every action and practice.

In framing learning and knowing in terms of action, I am taking up a position in relation to where interest in professional knowledge lies. Young and Muller (2014; see Chapter 1) describe a continuum between knowledge and action, suggesting the distinction they draw between them is analytical (rather than actual, I suppose). They feel Jensen et al (2012) go too far in the direction of 'can do' and 'practice', overlooking specialized knowledge, suggesting Guile's (2014) contribution to their volume bridges these two sets of interests (see also Guile 2012). I am inclined towards the practice-focused approaches. While the work of Jensen and colleagues (see also Nerland 2012; Nerland \& Jensen 2012, 2014) favours the idea of knowledge over Gherardi's knowing, both are drawn close to the action, to what is done. In the examples I provide below, more stable forms of specialized knowledge and spontaneous knowing can both be traced, without constructing them as opposing or pulling apart.

\section{Learning as connecting, and intimate outsidership}

Professional learning plays a crucial connecting function on the Unit. New textures are created, through practices of professional learning, i enabling professionals to become 'intimate outsiders' in their relationships with families. Intimate outsidership is discussed as a key theme below. As well as creating new textures, existing ones are maintained, modified, restored and repaired through learning; the perpetuation of practices in circumstances of change also requires learning that 
works at the level of connections in action. Such textures can comprise a range of temporal, spatial, embodied and material forms, as detailed in depth in Part II. Connectedness in action does not achieve itself, it is a sociomaterial, practical accomplishment, at times an deliberate product of professional work, at others a byproduct of work oriented primarily around other ends. Once established, textures do not self-perpetuate or self-propagate. Their maintenance requires work, particularly given that we may assume stability and change to be continually present as any professional practice unfolds. Circumstances change, requiring new textures to be fashioned, or existing ones to be adapted - through practices I conceive as professional learning. Textures, including those of intimate outsidership, can be more or less fragile, vulnerable to being distorted or broken. Professional learning performs functions of textural restoration and repair.

Staff on the Unit become intimate outsiders in family life. I borrow the concept of intimate outsidership from Ganong $(1995,2011)$ who suggested the notion in relation to his position as a social scientist working in a school of nursing. Ganong described an 'ambiguous bond' with family nursing research - on the one hand a depth of knowledge, attachment or commitment, and sharing in daily routines, joys and strains (intimacy), and on the other hand, a preserved and useful sense of detachment and otherness (outsidership). Hayes' (1995) response to Ganong's first review of family nursing research observed that the distance between intimate outside and unwelcome intruder is a short one.

This strikes at the heart of one of the key challenges faced by staff on the Unit. In order to do their work, to help bring about positive change in families, they have to balance intimacy and outsidership. Intimacy is borne of sharing in experiences and difficulties that are often private - chronic struggles with parenting, tensions between parents, feelings of failure, depression, and perhaps domestic violence. Staff are there during toddler tantrums, mealtimes, and in the middle of the night. They are witness to breakdowns, and see many parents when they are at their most vulnerable and fragile. Such intimacy is crucial: without a detailed living knowledge of parents and the challenges they face, it is hard to bring about change. As pointed to in Part II, and developed below, this intimacy is highly embodied, sensorial, developed through co-presence, and attuning to sounds, expressions, postures and gestures, as staff come to know by observing, listening to parents and children.

At the same time, outsidership remains crucial, too. It is by virtue of being outsiders that professionals are able to intervene, to offer different perspectives. In the language of FPM, this is referred to as challenging parents' constructs). For example, a playroom coordinator or nurse, as outsider, might to notice and draw attention to ways a child shares toys with her sibling, when all a parent sees is a tantrum-in-waiting (see Chapter 10 for more on pedagogies based on noticing). As outsiders, professionals on the Unit can engage with a particular family, drawing 
on their much wider knowledge and experience of other families. They draw on patterns, repertoires of strategies, and so on that constitute shared general understandings. When a mother describes how her daughter gets so extreme in tantrums that she throws up, a nurse might respond "Ah, she's a vomiter". Here the outsider is speaking, albeit in an intimate exchange: the professional who has seen this before, referring to knowledge of lots of families. Staff are also outsiders in the sense that they always part ways with families at the end of a week. Their trajectories cross and interweave for five days on the Unit, and (as described in Chapter 6), the spaces of home and the Unit are woven together, but staff are not living participants in family life at home.

What has intimate outsidership got to do with learning? Intimacy is not a given, it must be accomplished, deliberately and effortfully, and is sometimes more easily done that others. It is through learning about families, producing connections between professionals and families, that intimacy is achieved. Intimate outsidership can be conceived as a kind of texture, or connectedness in action. This does not render it as a static kind of state, but rather as a condition always tied to an unfolding, incomplete, and contingent process of learning. Intimate outsidership is less a body of knowledge, more an emerging form of knowing in practice. It is a question of enactment, of doings and sayings that weave intimacy and preserve outsidership. It involves work that is never finished, and always subject to revision. Changes may occur within the families with whom professionals have intimateoutsider relations, they may occur in the relationship between professionals and families, or in the circumstances surrounding either party. Each change produces a fresh imperative for professional learning, and acts as a catalyst for this. Professional learning is key to the monitoring and regulation of intimate outsidership, both in terms of individual relations with family members, and in terms of the wider corpus of staff.

Outsidership also relies on professional learning if it is to be mobilised or translated productively as a texture that has meaning and impact within the broader ends of bringing about positive change in families. The relating what is known about particular families to general understandings - wider bodies of knowledge and expertise about parenting and child development, and processes of change in families - accomplished through processes of learning. Textures of intimate outsidership have little meaning on their own. While they are constituted in connections in action themselves, to take effect they must be connected with other actions, other forms of knowing in practice.

Learning is also key to the processes through which staff collectively monitor the balance between intimacy and outsidership, wary of the ease with which they might tread into the embodied space of 'unwelcome intruder'Levels of comfortable intimacy between staff and a mother may not be shared with a father who has not been present in earlier in the week. Staff may have to step back, allowing 
some connections to break, while seeking to establish new ones with the father. These are reported and discussed in handovers, and inform subsequent actions. Over time, former textures of intimacy may be restored, though of course never quite the same. On other occasions, family members may question staff involvement and support because they appear overly outside the family: they don't know this child, their problems and needs. In this case, active listening, questioning and a range of practices of attuning are triggered in order to create a sense of intimate outsidership that in turn produces levels of comfort and trust in families.

Intimate outsidership is associated with its own connecting functions, and with others that link actions across the Unit. Intimate outsidership connects what staff do with the families in residence each week. It is, at the same time, a product of these interactions. Staff get to know families through practices of attuning. This attuning feeds knowing in practice that interacts with more stable professionalized forms of knowing (practical and general understandings), informing aesthetic judgements made from moment to moment about the standing of the relationship between staff and a family, what seems likely to work in terms of supporting parents, what they will accept, and so on. Not all professional learning is associated directly with changing forms of intimate outsidership. The textures of intimate outsidership are folded into other practices which mean that intimacy does not have to be re-learned and re-established from scratch every time a new professional interacts with a family. Handover is the most regular of these practices, along with case conference and staff briefings. Through these practices, intimate outsidership becomes part of a wider connective tissue - knowing in practice across a shift and from shift to shift.

Intimate outsidership does not only serve connecting functions. It also helps to sensitise practices to the (changing) circumstances priorities, strengths and vulnerabilities of each family. This is central to the idea of partnership. When we explore this feature of intimate outsidership, we see how it is not a question of a smooth, singular and linear trajectory from first meeting to knowing particular details about a family. Rather knowing in practice and associated textures of intimacy and outsidership are multiple, non-linear, fluid, contingent, fragile, and based on an epistemology of uncertainty. It is to these ideas that I turn in the next section.

\section{Learning as sensitising - working with epistemologies of uncertainty}

Learning plays a crucial role in sensitising the work professionals do on the Unit to the circumstances of each family. Alongside the connecting functions pointed to above, learning in professional practices of the Residential Unit also enables those practices to respond to changes, making them sensitive to subtle variations, pre- 
venting rigidity or stasis. This aspect of learning arises through and reflects particular views of knowledge, without which many imperatives to learn in the course of working with families would simply disappear. A key argument here is that epistemologies of uncertainty are crucial in the enactment of partnership on the Unit.

In this section I will show how professional knowing in practice is based on an epistemology that treats knowledge of families and how to support them as:

1. Incomplete - there is always more that could be known, and often the extent of partiality is itself not known.

2. Uncertain - not grounded in solid, stable 'facts', but treated as fragile.

3. Provisional and changing - only ever treated as 'what we know for now'

4. Informing rather than directing what to do next - there is always a 'gap' between present knowing and what would 'seal up' all questions of how to act; this gap is filled, to a working rather than complete extent, by personal and collective judgements and discussion.

5. Aesthetically based and performed - founded upon forms of attuning that are qualitative, personal, and often hard to articulate (although shared vocabularies and symbols, as used on behavior charts - see Figure 5.1 - and in handover conversations, help to mitigate this).

The idea that practices proceed amid uncertainty is not new. Jensen et al (2012) suggest that professional expertise includes knowing how to deal with uncertainty, rather than mere application of firmly held knowledge that determines action. Middleton and Brown (2005) make a similar point in their analysis of practices of neonatal intensive care. They describe work as characterized as much by ambiguity and uncertainty as by clarity and procedure. Indeed they suggest ambiguity can be seen as a resource. They saw the identity and status of babies as unsettled, enacted in multiple ways (see also Mol 2002), becoming actualized through a network of expertise, care and treatment. Similarly in the account that follows I show how families on the Unit are discussed, enacted, and learned about in multiple ways.

These points can be stressed through consideration of their converse. Professionals on the Unit do not act from a state of full knowledge, and what knowledge they have is not worked with in binaries of truth and falsehood, nor is it assumed to be perpetual. Knowledge of families, combined with repertoires and reservoirs of formalized and codified professional knowledge, never suffice to fully specify what should be done next. There is always a residue of tentative judgement, exploration, venturing into the unknown and unknowable.

Knowledge about families and how best to support them is not static. Rather it is fluid, subject to revision and reworking in non-linear, emergent ways. A default assumption might be to see knowledge about families as an entity that gets estab- 
lished early on, through referrals, intake, and admission, and then transferred or passed around the Unit. This simply does not hold up in the face of how practices unfold. It would not hold up even if this were adjusted to accommodate a knowledge-building trajectory that lasts the full duration of each week-long stay. Metaphor of addition or accrual do not do justice to, or accurately reflect, the complex knowledge work going on. While there are, of course, some relatively stable features of knowledge about a family (number, ages, and names of children, for example), the important working knowledge is much more fluid. In fact, as mentioned above on one occasion the apparently simple 'fact' of how many children a particular mother had, proved to be unstable and multiple working versions of the fact were enacted (this mother had lost a child and sometimes described herself as a mother of three, sometimes as a mother of two). So professional learning in practice here is not a question of discovery and transfer of fixed knowledge about families.

Knowledge about families is multiple, emergent, and sociomaterially enacted. This is in explicit contrast to singular, additive, and cognitive views. The practices of learning through which this knowledge is generated, interpreted and acted upon by the whole body of staff are sensitive to these knowledge conditions. When I say that this knowledge is multiple, I am borrowing from Mol's (2002) notion of multiplicity in the sense that what appears to be a single entity can be enacted into multiple beings (simultaneously and sequentially). Rather than thinking of what is known about each family, I think of how knowing about each family is enacted. Through this we can trace multiple ways of knowing, we can accommodate how plural 'truths' may be understood and acted upon, and we can explore professional practices on the Unit without requiring an ultimate resolution on a singular correct set of facts. This is important, because the practices I observed showed no signs of the latter approach to knowledge about families.

Professionals on the Unit know the families they are supporting in nonrepresentational ways. In arguing this, I draw on Thrift's (2007) ideas, without claiming that staff would recognize or share this as a descriptor of their way of working. Their knowing is non-representational in the sense that it does not proceed on principles that treat what is known as a complete and totally accuracy mirror of the reality of each family. Learning in professional practice on the Unit is based on a particular epistemology.

What professionals know about families is always treated as contingent, uncertain, and accompanied by not knowing (see Jensen \& Christiansen 2012). This is not an epistemology based on truth value, but an epistemology of emergence, complexity and conditionality. Emergence points to the fact that knowledge does not accrue in a linear fashion, but rather may leap forward, loop back, split off and run in parallel. The shape of what is to be known is uncertain, itself not known, and processes of coming to know do not follow a linear course. What is known is known only 
through actions that are always social and material. In referring to complexity I am pointing to the non-predictability of knowing, that similar epistemic conditions responded to in similar ways do not produce similar knowledge outcomes. And by conditionality, I mean 'it depends': knowing about families is not independent of the questions being asked and potential responses in action being considered. Rather it is bound up with these, shaped by, and inseparable from them.

Professional knowing about families is dynamic partly because those families are themselves changing. A central tension of professional learning on the Unit lies in the fact that if the overall practices of the Unit are being effective, then changes are being brought about in families. The pedagogic practices of supporting parents (see Chapter 10) create constantly shifting 'things' to be known. In some ways, learning about families is 'catching up' with what has happened for that family over the past few hours. But equally, learning about families 'leads' those changes because it informs and shapes the pedagogic practices that bring them about. Here we can see complex temporalities (see also Chapter 5) that undermine notions of learning as what enables practice by being completed in advance. Thus we start to see how the idea of partnership as reciprocal learning between professionals and families has deep roots, grounded in epistemologies of what it means to know each family and act on that knowing for each family. These epistemological issues have a significant bearing on intimate outsidership.

Intimacy is both a vehicle for learning about families (creating, modifying, adapting knowledge and associated connections in action), and an outcome of ways of knowing families 'close-up). As such it is never taken for granted as complete, certain, or done. There are some things about families that it is always important to know (caregivers, ages of children, incidence of domestic violence, experience of mood disorders, priority goals etc). Highly choreographed processes of admission and nurse-nurse handover function as ways to ensure that knowing covers this ground, although they do not secure what is known. But there is always a residue, sometimes larger, sometimes smaller, of particular aspects about each family that come to be known, that emerge as crucial foundations for future actions. The focus of these could not be specified or anticipated in advance (recalling the language used by Hager 2011). The unknown unknowns mean that one can never be quite sure what intimacy would comprise in the ways of knowing a particular family. Nor can one be sure when present knowing is sufficient (or too much).

Learning in professional practice proceeds in patterned but particular ways. Yes, there are some broad 'horizons of knowledge' towards which learning process are oriented, and to which the practices of learning on the Unit are prefigured. But the trajectories of knowing from first contact to intimate outsider facilitating positive change cannot be mapped or anticipated in advance. It is not known what paths such a trajectory will take, where it will end up, how far it will go, and whether indeed it is one trajectory or several. The practices of learning about families de- 
scribed below are practices through which professionals make sense of what to do next. This is based on 'what we know now' being treated as emergent, complex and conditional. Actions taken are themselves subject to those same qualifiers: outcomes may be anticipated or hoped for, prefigured, but never guaranteed.

Understanding the epistemology of knowledge that is enacted in the daily work of the Unit is crucial to understanding professional learning in practice. Some such practices are ways of coping with epistemologies of emergence, complexity and conditionality, when there is never the option of not acting, not taking what is known (and not known) into account. Some practices are a result of these epistemologies, ways of learning that have taken root because knowledge about families is unstable, uncertain, contingent and always incomplete.

Key aspects of learning in professional practice on the Unit can therefore be understood as epistemic work (see Jensen \& Christiansen 2012). Much learning is not just focused on coming to know certain things about a family and using this to inform what to do next (although this is clearly important). Significant components of professional learning in this setting concern the nature and status of knowledge itself - learning that addresses questions such as: What do we know? What don't we know? How known are these unknowns? How stable is this knowledge? How certain? How stable is the 'thing' (the family) to which this knowledge relates? How should we respond? These learning practices also accomplish epistemic work in the sense that they not only create knowledge, but act to test and secure it (however tentatively and provisionally) through textures of times, spaces, bodies and things.

This connects with wider features of knowledge and expertise in contemporary professional practices. Jensen et al (2012) write of expert knowledge being contested and branded with uncertainty, professionals not only applying knowledge in practice, but engaging in activities to 'explore, test, archive, validate and share knowledge' (p 4). We will see below how behavior charts become enacted as epistemic objects when folded into particular handover practices. For now my point is to establish that learning through professional practices on the Unit involves 'working ways of working with knowledge'. This goes way beyond applying knowledge, or even learning to acquire and transfer knowledge about families. These rely on metaphors of learning based on knowledge as entity, acquisition, representation and transfer. Instead I focus on learning as accomplished through particular practices, in which new knowledge emerges alongside and through actions and objects that call that knowledge into question. Thus 'what to do next' is never sealed or straightforwardly directed by what is known.

This brings us back to the issue of partnership between professionals and families. Models centred on professional expertise rest on notions of secure professional knowledge being applied to problems experienced by others. Actions to learn 
about families and customize one's professional response to them do not accomplish partnership in the sense set out in the FPM (Davis \& Day 2010) and similar frameworks. Attending to the epistemic features of professional learning in practice provides a useful lens through which to understand what partnership means in practice and how it is accomplished. The idea of 'reciprocal learning' between professionals and (in this case) parents is a basic foundation of my approach. I have foregrounded the contingent and incomplete nature of what and how professionals learn about the families they are supporting. The epistemologies that are enacted on the Unit, and the epistemic work that is performed as a means to cope with knowledge that is never certain, stable or complete, are both crucial to establishing and maintaining meaningful and effective partnerships with families.

Given all the uncertainty and incompleteness, how does anyone ever act? This is a crucial question. A practice theory approach helps us see that acting is not predicated on a condition of total security of knowing one is doing the 'right' or 'best' thing, with a known outcome. Rather it is a question of what it makes sense to do, where this sense-making is not just a property of individual knowledge and judgement (though these are important), but a property of social and material relations, textures of times, spaces, bodies and things. What to do next is prefigured but never sewn up. Responses in conditions of uncertainty and emergence are patterned through practices - in this case practices of learning that accomplish epistemic work as well as bringing forth knowledge about families.

Having explored the connecting (textural work) and sensitising (epistemic work) functions of learning in more conceptual terms, I now turn to handover practices as a specific and rich empirical reference point through which to illustrate and develop these ideas further.

\section{Handover as professional learning in practice}

This final section folds the key ideas presented so far in this chapter together. I build on the notion that partnership produces constant imperatives for professional learning in the ongoing conduct of work. I take as a foundation the practices of attuning, and a detailed understanding of what they involve and the forms of knowing they can produce (as discussed above and in Part II). And I explore how handover can be understood in ways that link these ideas to concepts of professional learning as connecting and sensitising, as performing textural and epistemic work.

In focusing on handovers I am not interested so much in the idea of handover as exchange of information. This would build on container and transfer metaphors that are inconsistent with a sociomaterial, practice-based approach. This is not to deny that information is not exchanged during handovers, but it is to argue that a 
much fuller understanding is grounded in alternative assumptions and concepts. In what follows there are a number of 'moves' in play. Handovers are treated as a practice, in Schatzkian terms, with the attendant concepts of activity, prefiguring, space of multiplicity, and materiality. Rather than seeing information in stable forms being transferred, handover is conceived as a site of learning, as much about changing ways of knowing as about connecting knowing from one person to another. Through these lenses, the functions of handover are described in textural and epistemic terms, and features of handovers, including material artefacts such as behavior charts (Figure 5.1), as well as their temporal, spatial and embodied patterns, take on new significance. Continuing the thread explored in relation to attuning, this approach presents handover as a means through which people mutually align and co-orient in practices that do not follow predictable paths (see Nicolini 2011).

Conceiving handover as performing textural work by my definition makes handover about learning that helps to produce, maintain, modify, repair, restore and maintain connectedness in action. This relies on textures of intimate outsidership which in turn are produced through practices of attuning. Handover as performing epistemic work means it is not just about reporting and sharing what is known, but questioning what is known, working with uncertainty, provisionality, and contingency, and asking, rather than assuming, what this all means for what to do next.

Handover constitutes a rich feature to 'zoom in' on (Nicolini 2009), providing an excellent basis to 'zoom out' and explore questions of knowing, learning and the shaping of practice. I distinguish between several different kinds of handover practices, as outlined in Table 9.1 below. In this way, I conceive handover in Schatzkian terms as a space of multiplicity, a thick horizontal plane in which both common and distinctive practical understandings, rules, teleoaffective structures, and general understandings produce patterned activities with common and distinctive characteristics.

Before going further, I should acknowledge other related work on handover practices. Nimmo (2014) offers an account of handover that grapples with ontological multiplicity, and sociomaterial enactments in ways that are echoed below. Billett and Smith (2014) describe handover as both transactional and transformative. Information is exchanged, but the subjects of handover - patients in this case - are also transformed, through changes to the course of action or its perpetuation if it is bringing about desired recovery. They suggest that handover, among other learning practices, brings diverse resources of practice together and makes them visible and accountable as learning.

Table 9.1 Distinctive handover practices

\begin{tabular}{lll}
\hline Kind of handover & Key details & Distinctive features \\
\hline
\end{tabular}




\begin{tabular}{|c|c|}
\hline Group / to the shift & $\begin{array}{l}\text { The in-charge nurse hands over to Involves the most people - all nurse } \\
\text { all the nursing staff about to start bodies for the coming shift arranged } \\
\text { their shift } \\
\text { around the handover room; all families } \\
\text { discussed; highly choreographed (see } \\
\text { below) }\end{array}$ \\
\hline Paired & $\begin{array}{l}\text { Colleagues hand over from one to Characteristic geometry of bodies } \\
\text { another. Either a nurse to the in- (nurses, charts, chairs), despite some } \\
\text { charge at the end of a shift, or mobility of location (handover room, } \\
\text { from one nurse to another who alternative venues); highly choreo- } \\
\text { will work with the same family (ifgraphed } \\
\text { 'with parents' option not possible' }\end{array}$ \\
\hline With parents & $\begin{array}{l}\text { The nurse who has been support- Highly fluid and unpredictable in } \\
\text { ing a family meets with the par- terms of location, geometries; some } \\
\text { ent(s) and the nurse assigned for patterning of content } \\
\text { the next shift }\end{array}$ \\
\hline On the fly & $\begin{array}{l}\text { When one nurse steps in for an- } \text { Operates on a 'need to know' basis, } \\
\text { other to take a break or attend to always located temporally and spatial- } \\
\text { another client } \\
\text { ly in the action with families }\end{array}$ \\
\hline
\end{tabular}

The account I offer below shares Billett \& Smith's (2014) move away from a purely transactional understanding of handover. It also develops some related but distinctive arguments, as listed below. I specify these by exploring the characteristics shown in Table 9.1 in more detail.

1. Handover practices emerge out of prior practices and prefigure subsequent ones. Handover looks back, anticipates, and shapes the future. More specifically...

2. Handovers build on performances of attuning and intimate outsidership accomplished by each staff member during their shift, and it shapes attuning work done by others in the next shift. Relational work is a strong characteristic, linked closely to attuning and intimate outsidership, and referenced to the idea of partnership.

3. Textural work is done as this attuning becomes folded into collective forms of knowing, producing connectedness in action, widening textures of intimate outsidership.

4. Epistemic work is performed as the epistemologies of handover embrace and work with uncertainty and contingency, rather than trying to reduce or eliminate these qualities.

5. Next steps are not determined by resolving around a single firm truth, but are negotiated and informed by complex forms of knowing. Subsequent actions are prefigured, not determined or dictated, and like what is known, are always provisional and contingent.

6. Handover practices on the Unit display patterns of movements, postures, speech, and use of objects. They can be understood as choreographed to varying degrees, and this choreography can be explained through practice theoretical concepts, including prefiguration. 
To expand on this final point, by choreography I refer to patterns of bodily arrangements and movements - bodies in space and time - with a strong emphasis on how they relate to each other and other things. I include in my use of the term what others might call a script. Choreography is a broader idea that includes sayings and doings. I am not the first to use this term in describing professional practices. Nicolini describes conducting a call in call centre work as 'a choreography in which the discursive and nondiscursive aspects blend seamlessly, constituting different moments of the same knowing' (2011, p 610). Goodwin's description captures much of what I have in mind:

The scene outlined here describes a routine bronchoscopy, in which a camera is passed into the patient's lungs. The 'routine' consists of an elaborate choreography coordinating the positions, movements, actions and responsibilities of materials and participants, moment by moment. (2007, p 263)

Thompson's (2012) view is slightly different. She refers to the choreography of overlapping work, work-learning and workplace spaces. These ideas also inform and can be traced in the discussion that follows here. Thompson also refers to the way in which a particular worker 'choreographs bits and pieces from all over' ( $p$ 264). This suggests that choreography is something that people do in practice, not just something they are subject to. This is important. There is a risk in using the metaphor of choreography that readers might infer a sense of practitioners unthinkingly following a set path that is accomplished through repetition and rehearsal of something that someone else has fixed in a bodily-discursive-material script.

On this point - that choreography does not imply predetermination of practices Whalen et al's work is very useful. They write of 'improvisional choreography', deliberately entangling two seemingly different, even opposed, ideas:

While 'improvise' and 'choreograph' may appear to be conceptually incongr ent, our
analysis demonstrates that even though these teleservice workers recurrently fabricate
their actions out of materials and means that are conveniently on hand, the convenience is
often carefully arranged to afford such extemporaneous composition. Finally, we
conclude from this analysis that the traditional topics of 'work routines' and
'routinization' need to be respecified in order to take into account how any 'routine' is a
contingently produced result (and in this centre, a craft-like performance). (2002, p 239).

Similarly when I write of choreography I thus refer to everyday and technical notions of the metaphor. The everyday sense hones in on the patterns and regularities in bodily movements, relationships, postures, and sayings - seeing handover as a kind of dance with distinctive, discernible forms. The technical notion points to overlaps between practice and learning, between improvising and repeating what is well rehearsed, and a sense that at any moment a professional can, through their actions and interactions, choreograph elements of their work. I conclude this section by exploring how Schatzki's concept of prefiguration provides a theoretical basis for precisely the working use of the metaphor I have described above. But 
first, I must make the case that established the choreographed effect. It is to this work that my attention now turns.

\section{Highly choreographed handovers}

Handovers at the intersection of each shift (see Figure 5.3) play a crucial role in enabling practices to hang together and respond to what arises in the coming hours. These may take paired form in which nurses assigned to work with particular families hand over to the colleague who will be working with the same families in the next shift. Arriving nurses may also receive handover as a group, from the in-charge, in which all families in residence are discussed. These practices rely on the temporal overlap between one shift and another, and produce rhythms of their own.

The group handovers constitute rare moments when all the nursing staff for a particular day shift are actually in the same room at the same time. At night, the two or three nurses often gather together at the nurses' station, but in all my observations I never witnessed a time when such a congregation occurred outside of group handover. Because weekly debrief happens in the middle of a shift, one or more nurses remains 'out on the Unit' attending to families. These handovers can be understood as a unique coming together of trajectories (Massey 2005), producing a spatial texture that is not found anywhere or anytime else. While there is a forward-moving trajectory here, in the sense that the past surges forward into the future, linking one shift to the next, there is also a more lateral joining together. For it is only here where all families in residence are discussed. The group handover is therefore a crucial site in which textures that encompass the whole resident population are woven together. The only other instance where trajectories of knowledge relating to all families come together occurs at night, when the clipcharts from each room congregate around the nurses' station (see Chapter 8 and Figure 8.4).

Similarly, trajectories come together in the paired handovers. Here it is more a question of a forward motion, fusing the chains of action from the last shift into those of the one about to happen. The narrower focus on two or three families assigned to each nurse allows for greater attention to detail in the content, drawing more fully on intimate outsidership and attuning in each relationship, but does not produce the wider texture of the group handover practices. The group approach provides all nurses with up to date (but still contingent, incomplete) knowledge about all families, enabling staff to act in for each other (see handovers on the fly below), and to maintain a general level of familiarity needed to offer passing acknowledgement or support to all clients when needed. The paired approach allows the nurses involved greater opportunity to share knowing connected with in- 
timate details of the behavior charts (see Figure 5.1) and other documentation. This is reflected in the contrasting choreographies of the two practices.

Both paired and group handover practices are strongly choreographed, as indicated in Table 9.1. However the specific geometries, movements, sayings and relations with objects are different. These reflect the different purposes and functions of each. In the group handover, handees (nurses beginning their shift) sit or stand around the edge of the room. They all have a clients in residence (CIR) sheet, and at least one pen; they all make notes on their CIRs, though what and how much is written varies. These written emphera create textures of things that carry actions and knowing forward from the previous shift into the next one (see Chapter 8; and also Nimmo 2014). They are also a key feature of paired handovers, but not so much the other two forms. The discussion follows a predictable script: while the specific details change from day to day and week to week, the issues covered tend to be relatively stable.

The paired handover features one of the most stable bodily-material geometries of any practice on the Unit. The choreography is highly distinctive here, not only in the arrangement of the bodies and objects, but also in their relative lack of movement. While there are gestures, nods, shifts in posture to share a glance at a behaviour chart, and so on, overall the handover is accomplished with little full body movement. There are always two nurses' bodies, seated around the corner of a table. The clipchart for the family being discussed is always on the table or held in a shared visual field. Figures 6.9 A-D in Chapter 6 illustrate the uniformity of this arrangement. What is remarkable is that this is reproduced even when the setting changes. Paired handovers take place by default in the handover room, but can also occur in the office of the paediatrician (VMO 1, see Figure 2.1). While the room, desk, and chairs may change, the arrangement does not. However, the choreography is not always identical. Other bodies and things are sometimes introduced, most particularly infants, which may be held in arms, or in prams which can be rocked forwards and backwards while handover takes place. This introduces elements of movement and rhythm that enrich the 'baseline' choreography.

I use the term choreography to stress patterns that are embodied and material, while also incorporating a more conventional sense of a script. Handovers on the Unit are scripted in the sense that the sayings are patterned in terms of its content and sequence. However the broader notion of choreography creeps back in as we notice that the spoken performances not only share attributes in words and meaning, but in tone of voice, rhythm of speech, and so on. The discussion takes each family in turn. On Mondays, key information arising from the admission is reported (outcomes of parenting confidence assessment, depression and domestic violence screening). On other days these may be mentioned, though this is often not needed as the information is available in the shared CIR sheet and many nurses read this and add notes to their own CIRs accordingly. When each family is dis- 
cussed, the in-charge will refer to her CIR, the shared CIR, and the clipchart(s) for each child (which contain the goals sheets, behavior chart etc). The priority goals agreed with parents are always discussed, as are judgements as to the wellbeing of each family member. Relevant episodes are recounted including the strategies implemented and their outcomes (in relation to settling, feeding, playtime, nightwaking etc). The latter has implications for the level of challenge that might be presented in the next shift.

Sayings in these handovers also always include discussion of the relationship between staff and each family (see Hopwood forthcoming). This might refer to how negotiations around goals proceeded, the extent to which staff feel they understand parents' values, experiences and priorities (contingent and incomplete knowledge being particularly explicit here), the level of trust and confidence parents appear to have in staff (which again has implications for challenge in the hours to come). This is crucial in the enactment of partnership. These professionals are attuning not only to children and parents, but to the connections in action between staff and families. The FPM holds that an open, honest, mutually respectful and trusting relationship is the conduit for helping families, setting these characteristics out as the conditions under which parents might be challenged in order to bring about change (Davis \& Day 2010; Day et al 2015).

Staff are clearly aware of such patterning and they place value in it. I say this because in instances where doings and sayings of one person deviate from the script, the other will take action to bring it back. When the anticipated form of connectedness in action does not materialize, staff fall back on a secondary set of practices to restore or repair the texture of handover. This could happen as follows:

Hander, reading from notes filled out during admission: So the mother in room five, she scored 32 on her KPCS, eleven on the EPDS and DV was negative. Her son is...

Handee, writing on her personal CIR sheet: Hang on, what did she get on ten?

Hander, looks back at her notes: Oh sorry, zero on ten.

Here the handee is listening to her colleague, filling out information, and anticipating a particular sequence in information. Her colleague accidentally misses out the mother's response to question ten in the depression screening which focuses on self harm and suicidal thoughts. The handee notices this immediately - a sign of how the pattern is anticipated - and interjects in order to correct it. That this constitutes a minor break in an expected flow is acknowledged by the hander when she says 'oh sorry'. Her notes provide the information for her immediately - they are as much part of the flow as the sayings of the hander, and the doings (writing on her personal CIR) of the handee. Handover is thus not only performed through ritual enactment of the choreographed routine, but also by constant monitoring for tears in the texture, and practices of restoration and repair that are mobilised when 
needed. These are not effected by one party, but remain folded into the social and material webs that constitute handing over.

Before moving on to consider other forms of handover, it is worth noting what is largely left out of these handovers. One might expect the sayings in handovers to be characterized by detailed discussion about parenting, settling children, dealing with toddlers and so on. In fact, the opposite is the case. Sleep routines, settling techniques, feeding practices and so on are discussed, but usually only in particular ways. One is in a descriptive report about what has happened - sayings elaborate on the knowledge recorded in the behavior chart. The other is to discuss how these relate to parents' goals: 'both her parents are very keen to get her to sleep without a breastfeed'. How to settle a child, respond to a tantrum, encourage solid food intake and so on are all, by and large, assumed and largely unproblematic features of professional expertise - general understandings. In some exceptional cases, when approaches from within the shared repertoire of strategies have not showed any promise, then the actual act of settling (or whatever the issue is) becomes something to be unpacked in handover. This happened once during my observations, with a boy who was highly unsettled for several nights and did not respond to any of the settling techniques they tried, and was eventually diagnosed with reflux.

If handover is not primarily about parenting techniques, what are the sayings focused on? The core business of handover comprises several linked areas of discussion (see Hopwood forthcoming). Handover discussions focus on what is known about the family (and the status of this knowledge, see below), the relationship between staff and the family, and what is known about how to help parents bring about the lasting positive change they are seeking. The first centres on what staff know about parents' existing constructs, their priorities and goals, strengths, resilience, emotional reserves and fragility, and so on. Such discussion is used in a process of gauging what strategies to try, what support to offer, and what challenge to present to parents (see Chapter 10, where this is discussed in terms of professional expertise being used to judge where a zone of proximal development lies for each family). The second involves exploring questions such as: How is the relationship between staff and families? How are we going in terms of establishing mutual trust, openness and honesty as a basis for negotiating what we do next? And the third involves discussion of goal related strategies and approaches - did the child respond to cot-rocking? If not, what might be tried today? Do the parents seem comfortable with gradual withdrawal? These are not discussed separately and in isolation, but rather each shapes and affects the other in a process I have described elsewhere as intra-mediation (see Hopwood forthcoming).

All this work is also permeated by epistemic work - work that is about knowledge. Here staff work together to assess and question what is known about each family. Handover is implicitly addressed to questions such as: What do we 
know? What don't we know? How certain is our knowledge? How important are the gaps? How can this inform what we do next? Even what might appear to straightforward 'facts' are opened up, as when a nurse might note that the behaviour chart record for the previous night might well be wrong or incomplete if the nurse writing it had to do so on the basis of sound emanating from the nursery alone, because the parents did not come out of the room or use the phone.

It is worth pausing here to comment on the CIR sheets and other objects in these handovers, notably the behavior charts (see Figure 5.1). Some references to these treat them as simple repositories of information, reading out names, ages, or times of waking, feeding, and so on. What handees write on their own sheets can similarly reproduce this information, as if a transfer model were in action. However, in this process, handees are making judgements as to what to write down, and are making connections between mundane facts (such as age) and wider, complex repertoires of professional knowledge (about child development, for example), and what they know about the family already. Whatever the unit of meaning, it is not being transferred in static form in this process, but rather made practically intelligible: selected, translated, (re)interpreted, and connected. The nurse assigned to work with that family will think through what it means for her shift, while her colleagues react differently to information about families they are not assigned to.

Behavior charts might are in some ways records of what has happened, and CIR sheets as systematically tabulated facts about families. As such they function as secondary artefacts (see Hopwood forthcoming; Wartofsky 1973). They drive questions of 'Who? What? When?' and 'In which location?', the latter including classifications and categories, such as the distinctions between grizzles, cries and screams shown in the behaviour chart on Figure 5.1 (see Engeström 2007).

However the function of these objects in handover is much more complex. It is around these, and perhaps also documents attached to behavior charts that outline parents' goals, that the most thorny handover discussions emerge. These objects give staff pause to ask questions, to surface dilemmas or uncertainties, to explore alternatives and options as to what to do next. As such they act as tertiary objects, or 'Where to?' tools (Engeström 2007; Hopwood forthcoming). In many instances, both in the group and paired handovers, the behavior chart and CIR sheets are enacted as epistemic objects (Knorr Cetina 2001). Epistemic objects create a dissociation between self and work, inserting moments of interruption and reflection. They are open-ended, incomplete or unfinished, inviting or generating questions; they are partial objects in relation to the whole. Families become knowledge objects when what is known and not known about them is brought explicitly into question (see Edwards \& Daniels 2012).

Quite often I observed handovers where behavior chart showed a flat line through a Monday night, indicating a child was settled throughout. However staff would 
discuss the fact that some cries were heard at different times, but the parents did not come out into the corridor or make telephone contact with the night staff. Therefore the child's sleeping and waking are not actually well represented, or even known to staff. The texture is weak. This sets an agenda for the nurse on the coming shift to work with parents to find out what happened over night, but also acts as a catalyst for a discussion about why the parents may not have contacted staff, and how this might best be broached under the rubric of partnership. On other occasions, staff noted a pattern on the behavior chart indicating good progress in terms of daytime sleep patterns, and explored the contrast between this and the reported feelings of the mother that things aren't changing for the better. Again the object is less a holder of stable information, and more a starting point, a window into discussions which call knowledge into question, probe and try to map the edges of what is known, and collectively deal with the contingencies, partialities and uncertainties in order to judge what to do next.

\section{Handing over with parents}

Not all handovers are a purely professional affair. Staff on the Unit try to conduct handover at least once a day with a parent also present (see Table 9.1). The more stable rhythms of the Unit produce some temporal patterns in these handovers, but also underpin their more sporadic nature. The inclusion of parents in handovers is associated in part with recommendations of the Garling Report (2008), which encouraged involvement of service users in handover at least once in each 24 hour period. However the involvement of parents in handover at Karitane predates this, and is also driven by the openness and negotiation that are characteristic of partnership and the enactment of the FPM.

I will now illustrate the varied performances involved in handover with parents by presenting a number of excerpts from my field notes. We begin with my first observation of this, a Wednesday:

I sat in on a handover, in the client's bedroom. Two nurses sat next to each other on the bed, while the Emily stood at the foot of the bed. Her toddler sat next to me on the sofa. They spoke about what the mother had been doing, praised her achievements, and praised the toddler. They also discussed some concerns Emily had about her husband back home not accepting the approach she has been trying out with her daughter. Emily commented that she found it hard at first but how she is finding the labeled praise is coming more automatically. The nurses explained that tomorrow they would withdraw a bit but still be on hand to help if needed.

Several weeks later, again a Wednesday, parental involvement in handover proceeded quite differently:

Nurses Pippa and Louise come into the playroom to find Terri, who is playing with her 10-month old daughter Annabel. They step over the fenced area for young infants, and sit 
my Terri on the mat. Pippa (who is handing over to Louise) tells the story of the morning, and Terri confirms adding details. Louise asks Terri about her priorities for the afternoon, what she wants to work on, and what she plans to do. Terri mentions breastfeeding and talks through her bottle plans, asking how much to give Annabel. Both nurses contribute a response, before Pippa offers a sheet for Terri to sign, which she does, using Pippa's pen.

And months into my fieldwork, my notes document these interactions:

Nurse Rachel comes into the playroom with her colleague Julia, to whom she is handing over for the afternoon shift. They sit around a table in the corner where Sofia is sat with her daughter Isabella. Sofia tells the nurses how delighted she is with how things are going, feeling much better. Rachel reports to Julia that they had a good nice. Sofia tells Julia (who had supported her the night before), 'I did what you told me', adding details as to what Isabella did, how she responded, and the effect it had on her daughter. Both nurses nod and smile. Rachel describes the morning settling and resettling, in which they didn't manage to get Isabella back for a second sleep cycle but 'it was good, though, we gave it a real go!'. Julia checks whether Sofia wishes to change anything regard her goals (no), and then they discuss how significant the changes are that have already occurred, particularly in terms of Sofia now talking about her daughter's cries meaning different things.

In just these three excerpts we have seen handover on the floor and around a table in the playroom, and around a bed and sofa in a client's room. My notes also describe similar interactions in a corridor, either stood around a nursery door, or even while walking, perhaps up to a client lounge or the outdoor play area. None of the stable and tight choreography in terms of body positions, geometries, relationships with furniture and other objects is evident here. Similarly the sayings are much more fluid - without an anticipated sequence, and covering highly variable content. The introduction of a third (and sometimes fourth, if both parents are present) party who is not familiar with the handover routine presumably contributes to this dynamism. Nurses often take their cues from what parents offer, how time pressed they are, how occupied with playing, settling, eating and so on, as well as how sensitive the discussion may be, bearing in mind that the space of handover may be more or less public (see Chapter 6).

This fluidity and variation is not an indication that these handovers are taken less seriously than the more choreographed ones. Often staff try to find parents in order to conduct a handover with them, but are unable to do so. Sometimes parents are asleep, or otherwise engaged with children that mean the rhythm of overlap between shifts does not coincide conveniently (eurrythmically, in Lefebvre's (2004) terms), with the rhythms of family activity. In such cases, staff simply conduct handover between themselves. The rhythms and movements of staff are much more stable and predictable, with staff anticipating handover needs, congregating around the handover room, or leaving messages with colleagues as to their whereabouts, so they can be found when needed, or the order of handovers adjusted. 


\section{Handing over on the fly}

The last of the handover handover practices summarized in Table 9.1 concerns handover that happens 'on the fly'. These arise as one member of staff steps in for another for a short period of time - usually so the former can go on a break, or sometimes because they are needed urgently to support another family. The focus here is much more narrow and immediate than in other handovers. More formal handovers cover much of what has happened and has been learned about at least two families, with the idea of passing one shift to another, including associated aspects such as progress made towards and changes in parents' goals, relational work and so on. When handing over on the fly, the exchange if confined only to the activity happening right now.

The broader relational and epistemic work described above are largely absent here, allowing for emphasis on what is concrete and immediate. These are usually conducted standing up, but actually reflect the geometries and postures of the ongoing activity rather than representing forms shaped by handover practices. If the handing over occurs during a meal time, it will be seated around a table; if it arises during play, it may be done on the floor or outside; and if during settling, it will usually involve standing by a nursery door. In such handovers it is very unusual for anything to get written down, unless one nurse writes on her wrist or palm, or continues adding information to a behavior chart - again more as part of the ongoing activity than as an artefact of handover.

Sometimes the exchange is so brief, it doesn't seem like a handover at all - but nonetheless the performance is one in which responsibility and involvement in unfolding activity are passed on from one member of staff to another. One such incident was documented in my fieldnotes thus, from a Tuesday morning.

Nurse Sarah opens the playroom door and calls down the corridor, "Can someone relieve me? I've got a meeting with Allied Health". Her colleague Bridget comes along, and introduces herself to the only family in the playroom at the time. Sarah leaves, and Bridget gets immediately involved in playing with the children and talking to their mother.

At other times, there is more explicit discussion, and in the example below, the parent was also directly involved:

I have been in a nursery while Nurse Pippa helps Eleni settle her son Michalis. Nurse Jayne, who is in-charge that day, comes up the corridor and asks Pippa if she can go for lunch now? Yes. Jayne gets Bridget to come and relieve Pippa, and when she arrives a brief handover is given. While the two nurses do most of the talking, eye contact, nods, and brief questions fold Eleni into the discussion. Pippa describes how they have been 
working on comfort settling, and praises Eleni for being ready to challenge Michalis.

Looking at her watch and the behavior chart, Pippa says they are good to go until $1 \mathrm{pm}^{3}$.

I documented handover on the fly in corridors, the playroom, dining room, around the nurses' station, in the handover room, client lounges, and in nurseries or bedrooms. These handovers are much less tightly choreographed than the formal paired or shift team practices. This does not mean that what is said and done, and the arrangements and movements of bodies and artefacts are wholly free of any shaping forces. On the contrary, these practices are prefigured just as in other handovers. However here this force is less tight.

\section{How is professional learning in practice choreographed?}

Having established that practices of professional learning in the course of work are choreographed, we are left with the question of how this happens. Based on my interpretation of Schatzki's practice theory, the answer lies not in finding a choreographer - or even choreographers - whose design and intent have resulted in the practices described above. Instead I find two points in Schatzki's conceptual terrain helpful in explaining such choreography: the relationship between practices and activities, and prefiguration. I note here that Schatzki doesn't write about choreography per se, and so here I am appropriating his ideas in order to explain a phenomenon that arose from my analysis, informed by Nicolini (2011) and others (Goodwin 2007; Thompson 2012; Whalen et al 2002).

What particular professionals do say in any particular handover can be understood as activities (Chapter 30. In Schaztki, we can conceive these as connected in multiple, bi-directional forms, with practices of handing over. This is signaled in Schatzki's oft-cited description of practices as 'embodied, materially mediated arrays of human activity centrally organised around shared practical understandings' (2001, p 2). Practices are spaces of multiplicity, thought of more as a slightly thick horizontal plane rather than in hierarchical terms. Thus we can speak of handover practices on the Residential Unit as a space of multiplicity made up of distinctive ways of doing handover. They can be considered versions of handover practices to the extent that they share the practical understandings, general understandings, ends (purposes, or teleoaffective structures) and rules of each other.

Any particular activity is shaped by the practice of which it is an instantiation, and at the same time it upholds, perpetuates or modifies that practice. 'Practice organi-

\footnotetext{
${ }^{3}$ This is not because they were using a 'controlled crying' approach (based on timing cries). Rather, there is a working rule of thumb that new settling techniques are tried for up to about 40 minutes, after which staff suggest parents switch back to whatever approach they have used in the past, such as holding in arms, or a breast feed.
} 
sations circumscribe activity. In turn, activity maintains practice organisations' (Schatzki 2010, p 212). Practice theory holds (as do many other sociomaterial approaches in their own ways) that the wider factors shaping particular actions are always 'there', expressed and manifest in each particular doing. As Kemmis and Grootenboer's (2008; see also Hopwood et al 2013) notion of practice architectures suggests, we do not need to look 'out there' for broad, external influences. Any influence is only ever exerted in the moment of particular doing. The same basic idea is there in Schatzki's idea that all actions produce and reproduce the factors that shape them.

So, we can understand the doings and sayings of any specific instance of handover as 'choreographed' by the practice of handing over. What people do and say, and the material arrangements amid and with which these performances are accomplished, proceed in more or less accordance with the practice of giving handover. The practice is by definition a relatively stable (though not static), and socially recognized (though not uncontested) form. A nurse giving handover recognizes and enact out the bodily performances (practical understandings), wider knowledge (general understanding), purposes (teleoaffective structures), and protocols and norms (rules) that are involved in handover. This recognition and capacity is shared with others, and the performances of handover thus display recognizable, patterned forms. This patterning, given the embodied, spatial, temporal, and material dimensions of practices and connections between them, produces the choreography we have observed.

How, then, can there be variations in handover practices - a space of multiplicity and how can they ever change? First, the shared understandings, ends and rules are not singular 'points' but are themselves multiple and accommodate variation. Second, a practice shapes or governs the activities that uphold it, but it does not wholly determine exactly what happens. In Schatzki, activities are indeterminate, meaning that until they occur, they are not fixed. At the moment of the performance, the understandings, ends, and rules in play may reproduce those of the wider pattern, or they may deviate. As such deviation becomes spatially and temporally dispersed, recognized and performed by others as a way of doing a particular practice, then the space of multiplicity is enriched, or the original practice may have been modified (see Schatzki 2010; Chapter 3).

To understand this and the choreography of handovers better, I turn to Schatzki's concept of prefiguration (see Chapter 3). This addresses the idea that practices are both patterned and yet open-ended at the same time. Prefiguration refers to the ways in which bundles of practices and arrangements shape what it makes sense to do, make particular courses of action easier, harder, simpler, more complicated, shorter, longer, ill-advised, promising of ruin or gain, riskier or safer, more or less feasible, and so on (see Schatzki 2002). Prefiguration does not clear some paths and obliterate others, but rather figures them with different qualities or associated 
intelligibility in terms of what it makes sense to do. Courses of action can be made more or less difficult, threatening, distinct, and so on.

So, handovers are prefigured, giving them patterned qualities that result in a choreographed effect (see Table 9.1). Let us consider the highly choreographed handover to the shift. The prefiguring forces here are strong and focused. The actions it makes sense to do given the purpose of handing over to an entire shift team, are highly circumscribed. There are limited venues where all the bodies can fit and converse in a private space out of earshot of families (see Chapter 6), and limited times at which this can occur, given the rhythms of shift patterns (see Chapter 5). Contrast this with handover involving parents, or handover on the fly. There is no single location, no specific arrangement of bodies and objects, no particular time or frequency, in which these practices make more sense, become simpler, more likely to succeed, less encumbered (etc.) than others. This does not mean that these kinds of handovers are not prefigured - they are - just that the prefiguring forces are more dispersed, less weighted clearly towards particular spatial, temporal, embodied and material forms. Thus we can explain the less choreographed qualities on display.

Before I consider connections between handover and the practices of working with families the precede and succeed them, it is important to make explicit the links between the framing of handover as practices of professional learning, and the conceptual discussion above. The idea of prefiguration depends crucially on the idea of what it makes sense to do. The implication is not that practices proceed according to a strict, linear rationalism devoid of any affective quality. However it does recognize that insofar as actions are oriented towards particular ends (which a Schatzkian approach holds central), people are likely to choose courses of action that lend themselves towards those ends. In the context of professional practice, the notion of professionalism becomes active, as do a wide range of laws, profession-specific rules, expectations, ways of knowing (epistemic communities - Jensen et al 2012), and so on.

So, I suggest that performances of handover are shaped by professionalized judgements as to what it makes sense to do, given particular ends. What are these ends? A surface reading might suggest transfer of information, or in the case of handover with parents, compliance with policy changes resulting from the Garling Report (2008). In contrast, I have framed handover as a practice of professional learning. In doing so I deliberately move away from the idea of transfer of information, towards something more interactive and emergent. The ends of handover can be understood in terms of the two functions of learning identified earlier: connecting and sensitising. In handover, nurses (and other professionals, and parents where relevant) are seeking to establish connections in action. These involve relational work and epistemic work. The sensitising function ensures that connections 
are held flexibly, reinforced and strengthened when there is evidence that things are working well for a family, provisional and ready to be altered until then.

The learning ends vary depending on the kind of handover, and exploring these helps give further sense to the forms described above. When handing over to the shift, the connecting function has a strong component of ensuring an entire shift team has a shared understanding of all the families in residence, and affords a sensitivity in interaction even between staff and non-assigned families. Paired nursenurse handover established a fine grained set of connections, and helps to fashion highly specific sensitivity, focusing on only two or three families, and getting into more detail in the relational and epistemic work: what do we know about how to work with this family, their goals, the support they need and will accept? What do we know about what seems to work in meeting their goals? Handover involving parents is shaped by aims to establish connections in action and sensitivity to a particular family, and make the connections visible to parents, as well as including parents directly in their determination. Handover on the fly is largely drive by establishing the connections needed to ensure continuity of support in a particular ongoing activity.

\section{Conclusions}

In this chapter I have moved the analysis of professional practice and learning forward. Building on the four-dimensional account of changing connectedness in action in Part II, I have presented a distinctive view of the learning that occurs as professional practices unfold, and how this happens. This counters disembodied and amaterial tropes, instead presenting learning as fundamentally constituted in the body, body work, and material arrangements. Equally the account complicates temporalities of learning, and connects with contemporary practice-based notions of space. Taking cues from and advancing what Hager (2011) describes as a third tranche of approaches to workplace learning, my account in this chapter reveals how professional practices demand learning as a never-finished part of ongoing work. This demand is intensified in practices that have been reconfigured around particular relational bases between professionals and service users, as in the present study where partnership with families is a crucial feature of work.

I have theorized learning in an asymmetrical, non-reversible relationship with practice - accomplished through and emerging in practices, but not a universal quality of them. Specifying this relationship further, I argue professional learning in practice involves the production, restoration, repair and modification of textures - which have temporal, spatial, embodied and material dimensions. It also involves the maintenance of connectedness in action when other things change. I have developed the notion of attuning - first presented in Part II - as a key feature 
of professional learning. This concept strikes at the heart of the post-Cartesian aspects of sociomaterialism and practice theory: it undermines hard separations between mind and body, and views knowledge as emergent and entangled through changing assemblages of people, actions, things, and sense-making.

Finally I have suggested that professional learning in practice performs two distinct but related functions: connecting and sensitising - accomplished through textural and epistemic work. This incorporates both Nicolini's (2011) notion of mutual alignment and co-orientation, and also Edwards' (2000) of practitioners repositioning themselves in relation to emerging practice knowledge, changing ways of making sense (interpreting) and opening up new possibilities for action. I have explored different kinds of handover practices in order to illustrate how learning enables practices to hang together, while also producing the agility and responsiveness that complex work requires. The notion of choreography is helpful in discerning and explaining patterns in the practices through which this learning is accomplished. In Chapter 10 I will continue to build on the ideas of Part II, but switch the gaze to look more closely at the professional learning that arises through and is entangled with the pedagogic aspects of working in partnership with service users.

\section{References}

Billett, S., \& Smith, R. (2014). Learning in the circumstances of professional practice. In S. Billett, C. Harteis \& H. Gruber (Eds.), International handbook of researching professional and practice-based learning (pp. 733-757). London: Springer.

Črnčec, R., Barnett, B., \& Matthey, S. (2008). Development of an instrument to assess perceived self-efficacy in the parents of infants. . Research in Nursing \& Health, 31(5), 442-453. doi: 10.1002/nur.20271

Davis, H., \& Day, C. (2010). Working in partnership: the Family Partnership Model. London: Pearson.

Day, C., Ellis, M., \& Harris, L. (2015). Family Partnership Model reflective practice handbook. London: Centre for Parent and Child Support for South London and Maudsley NHS Foundation Trust and King's College London.

Dunston, R., Lee, A., Boud, D., Brodie, P., \& Chiarella, M. (2009). Co-production and health system reform - from re-imagining to re-making. The Australian Journal of Public Administration, 68(1), 1-14. doi: 10.1111/j.1467-8500.2008.00608.x

Edwards, A. (2000). Looking at action research through lenses of sociocultural psychology and activity theory. Educational Action Research, 8(1), 195-204. doi: 10.1080/09650790000200104

Edwards, A., \& Apostolov, A. (2007). A cultural-historical interpretation of resilience: the implications for practice. Critical Social Studies, 9(1), 70-84. doi: NA

Edwards, A., \& Daniels, H. (2012). The knowledge that matters in professional practices. Journal of Education and Work, 25(1), 39-58. doi: 10.1080/13639080.2012.644904

Engeström, Y. (2007). Enriching the theory of expansive learning. Mind, Culture and Activity, 14(1-2), 23-29. doi: 10.1080/10749030701307689 
Fenwick, T. (2012). Coproduction in practice: a sociomaterial analysis. Professions \& Professionalism, 2(2). doi: 10.7577/pp/v2i1.323

Fowler, C., Dunston, R., Lee, A., Rossiter, C., \& McKenzie, J. (2012a). Reciprocal learning in partnership practice: an exploratory study of a home visiting program for mothers with depression. Studies in Continuing Education, 34(2), 99-112. doi: 10.1080/0158037X.2011.611800

Fowler, C., Lee, A., Dunston, R., Chiarella, M., \& Rossiter, C. (2012b). Co-producing parenting practice: learning how to do child and family health nursing differently. Australian Journal of Child and Family Health Nursing, 9(1), 7-11. doi: NA

Ganong, L. (1995). Current trends and issues in family nursing research. Journal of Family Nursing, l(2), 171-206. doi: 10.1177/107484079500100204

Ganong, L. (2011). Return of the 'intimate outsider': current trends and issues in family nursing research revisited. Journal of Family Nursing, 17(4), 416-440. doi: $10.1177 / 1074840711425029$

Garling Report. (2008). Final report of the Special Commission of Inquiry: acute care services in NSW public hospitals. Sydney: State of NSW.

Gherardi, S. (2006). Organizational knowledge: the texture of workplace learning. Oxford: Blackwell.

Goodwin, D. (2007). Upsetting the order of teamwork: is 'the same way every time' a good aspiration? Sociology, 41(2), 259-275. doi: 10.1177/00380385070749

Guile, D. (2012). Inter-professional working and learning: 'recontextualising' lessons from 'project work' for programmes of initial professional formation. Journal of Education and Work, 25(1), 79-99. doi: 10.1080/13639080.2012.644908

Guile, D. (2014). Professional knowledge and professional practice as continuous recontextualisation: a social practice perspective. In M. Young \& J. Muller (Eds.), Knowledge, expertise and the professions (pp. 78-92). Abingdon: Routledge.

Hager, P. (2011). Theories of workplace learning. In M. Malloch, L. Cairns, K. Evans \& B. N. O'Connor (Eds.), The SAGE handbook of workplace learning (pp. 17-31). London: Sage.

Hayes, V. E. (1995). Response to L. H. Ganong: "Current trends and issues in family nursing research". Journal of Family Nursing, 1(2), 207-212. doi: 10.1177/107484079500100205

Hook, M. L. (2006). Partnering with patients - a concept ready for action. Journal of Advanced Nursing, 56(2), 133-143. doi: 10.1111/j.1365-2648.2006.03993.x

Hopwood, N. (2013). Understanding partnership practice in primary health as pedagogic work: what can Vygotsky's theory of learning offer? Australian Journal of Primary Health. doi: 10.1071/PY12141

Hopwood, N. (2014). A sociomaterial account of partnership, signatures and accountability in practice. Professions \& Professionalism, 4(2). doi: 10.7577/pp.604

Hopwood, N. (forthcoming). Expertise, learning, and agency in partnership practices in services for families with young children. In A. Edwards (Ed.), Collaborating on complex problems: cultural historical accounts of relational work. Cambridge: Cambridge University Press.

Hopwood, N., \& Clerke, T. (2012). Partnership and pedagogy in child and family health practice: a resource for professionals, educators and students. Hertsellung: Lambert Academic Publishing.

Hopwood, N., Fowler, C., Lee, A., Rossiter, C., \& Bigsby, M. (2013). Understanding partnership practice in child and family nursing through the concept of practice architectures. Nursing Inquiry, 20(3), 199-210. doi: 10.1111/nin.12019

Jensen, K., \& Christiansen, B. (2012). New patterns for epistemic engagement in nursing. In K. Jensen, L. C. Lahn \& M. Nerland (Eds.), Professional learning in the knowledge society (pp. 211-228). Rotterdam: Sense Publishers.

Jensen, K., Lahn, L. C., \& Nerland, M. (Eds.). (2012). Professional learning in the knowledge society. Rotterdam: Sense Publishers. 
Kemmis, S., \& Grootenboer, P. (2008). Situating praxis in practice: practice architectures and the cultural, social and material conditions for practice. In S. Kemmis \& T. J. Smith (Eds.), Enabling praxis: challenges for education (pp. 37-63). Rotterdam: Sense.

Knorr Cetina, K. (2001). Objectual practice. In T. R. Schatzki, K. Knorr Cetina \& E. von Savigny (Eds.), The practice turn in contemporary theory (pp. 175-188). London: Routledge.

Lefebvre, H. (2004). Rhythmanalysis: space, time and everyday life. London: Continuum.

Massey, D. (2005). For space. London: Sage.

Middleton, D., \& Brown, S. D. (2005). Net-working on a neonatal intensive care unity: the baby as virtual object. In B. Czarniawska \& T. Hernes (Eds.), Actor-network theory and organizing (pp. 307-328). Copenhagen: Copenhagen Business School Press.

Mol, A. (2002). The body multiple: ontology in medical practice. London: Duke University Press.

Nerland, M. (2012). Professions as knowledge cultures. In K. Jensen, L. C. Lahn \& M. Nerland (Eds.), Professional learning in the knowledge society (pp. 27-48). Rotterdam: Sense Publishers.

Nerland, M., \& Jensen, K. (2012). Epistemic practices and object relations in professional work. Journal of Education and Work, 25(1), 101-120. doi: 10.1080/13639080.2012.644909

Nerland, M., \& Jensen, K. (2014). Changing cultures of knowledge and professional learning. In S. Billett, C. Harteis \& H. Gruber (Eds.), International handbook of researching professional and practice-based learning (pp. 611-640). London: Springer.

Nicolini, D. (2009). Zooming in and out: studying practices by switching lenses and trailing connections. Organization Studies, 30(12), 1391-1418. doi: 10.1177/0170840609349875

Nicolini, D. (2011). Practice as the site of knowing: insights from the field of telemedicine. Organization Science, 22(3), 602-620. doi: 10.1287/orsc.1100.0556

Nimmo, G. (2014, 25-27 June). Materialities of handover in intensive care. Paper presented at the ProPEL International Conference - Professional Matters: Materialities and Virtualities of Professional Learning, Stirling.

Price, O. M., Johnsson, M. C., Scheeres, H., Boud, D., \& Solomon, N. (2012). Learning organizational practices that persist, perpetuate and change: a Schatzkian view. In P. Hager, A. Lee \& A. Reich (Eds.), Practice, learning and change: practice-theory perspectives on professional learning (pp. 233-247). Dordrecht: Springer.

Rossiter, C., Fowler, C., Hopwood, N., Lee, A., \& Dunston, R. (2011). Working in partnership with vulnerable families: the experience of child and family health practitioners. Australian Journal of Primary Health, 17(4), 378-383. doi: 10.1071/PY11056

Schatzki, T. R. (2001). Introduction: practice theory. In T. R. Schatzki, K. Knorr Cetina \& E. von Savigny (Eds.), The practice turn in contemporary theory (pp. 1-14). London: Routledge.

Schatzki, T. R. (2002). The site of the social: a philosophical account of the constitution of social life and change. University Park, PA: Pennsylvania State University Press.

Schatzki, T. R. (2003). A new societist social ontology. Philosophy of the Social Sciences, 33(2), 174-202. doi: $10.1177 / 0048393103033002002$

Schatzki, T. R. (2010). The timespace of human activity: on performance, society, and history as indeterminate teleological events. Lanham, MD: Lexington.

Schatzki, T. R. (2013). The edge of change: on the emergence, persistence, and dissolution of practices. In E. Shove \& N. Spurling (Eds.), Sustainable practice: social theory and climate change (pp. 31-46). London: Routledge.

Thompson, T. L. (2012). (Re/dis)assembling learning practices online with fluid objects and spaces. Studies in Continuing Education, 34(3), 251-266. doi: 10.1080/0158037X.2011.613377

Thrift, N. (2007). Non-representational theory: space, politics, affect. Abingdon: Routledge.

Wartofsky, M. W. (1973). Perception, representation and the forms of action: toward an historical epistemology. In M. W. Wartofsky (Ed.), Models: representation and the scientific understanding (pp. 188-120). Dordrecht: Reidel. 
Whalen, J., Whalen, M., \& Henderson, K. (2002). Improvisational choreography in teleservice work. British Journal of Sociology, 53(2), 239-258. doi: 10.1080/00071310220133322

Young, M., \& Muller, J. (Eds.). (2014). Knowledge, expertise and the professions. Abingdon: Routledge. 